\title{
Obituary
}

\section{Jillian Russyll (AKA Jill) Tate}

https://doi.org/10.1515/cclm-2018-2394

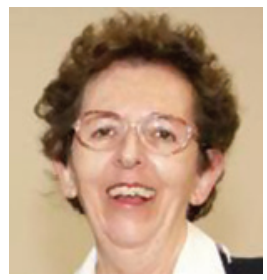

With deep sorrow we announce that on December 4, 2018 we have lost a good friend, a nice colleague, an esteemed scientist and an Associate Editor of Clinical Chemistry and Laboratory Medicine.

Jill Tate died after a long illness which she faced with courage and endurance. Although the disease did not allow her to work so hard in the last few months as she did throughout her career, she expressed her joy in assisting with the publication of the special issue on "Harmonization in Laboratory Medicine: the Request, the Sample, the Measurement, and the Report" which was conceived, managed and published only thanks to Jill's enthusiastic and devoted work.

Jill, in fact, was the Chair of the Australasian Association of Clinical Biochemists' Harmonisation Committee and worked on a wide range of harmonization activities, including common reference intervals, standardized measurement units, terminology and reporting in laboratory medicine, as well as critical results notification, activities which are now universally recognized as "the global picture of harmonization in laboratory medicine”.

Although Jill worked as a Senior Scientist at the Pathology Queensland Department of Chemical Pathology at the Royal Brisbane and Women's Hospital in Brisbane, her invaluable contribution to the advancement of laboratory medicine needs to be acknowledged.

Jill chaired the International Federation of Clinical Chemistry and Laboratory Medicine (IFCC) Working Group for the Standardization of Cardiac Troponin I (IFCC WG-TNI), and previously participated in the IFCC Committee on Standardization of Markers of Cardiac Damage and the IFCC Working Group on Standardization of Lipoprotein(a).

Along with dozens of other papers in leading journals, she published several seminal papers, including those on interference in immunoassays [1], measurement uncertainty [2], standardization of cardiac troponin I immunoassays [3], reporting of serum protein electrophoresis to clinicians [4], and many other innovative and interesting articles.
We wish to particularly recall that she was, and she will remain, an archetype for many laboratory professionals because, along with her exceptional competency and expertise, she was always humble and supportive during her lifetime devoted to science in the service of humanity. She will be remembered with love, affection and respect by all those who knew her, especially by her friends and colleagues.

\section{References}

1. Tate J, Ward G. Interferences in immunoassay. Clin Biochem Rev 2004;25:105-20.

2. Tate JR, Plebani M. Measurement uncertainty - a revised understanding of its calculation and use. Clin Chem Lab Med 2016;54:1277-9.

3. Panteghini M, Bunk DM, Christenson RH, Katrukha A, Porter RA, Schimmel $H$, et al. Standardization of troponin I measurements: an update. Clin Chem Lab Med 2008;46:1501-6.

4. Tate JR, Mollee P, Gill D. The reporting of serum protein electrophoresis to clinicians. Clin Chim Acta 2005;358:204-5.

Corresponding author: Professor Mario Plebani, Department of Laboratory Medicine, University-Hospital of Padova, 35128 Padova, Italy, Phone: +390498212792,

Fax:+39049663240, E-mail: mario.plebani@unipd.it

Philippe Gillery

American Memorial Hospital, Laboratory of Pediatric Biology and Research, CHU Reims, Reims, France

Heike Jahnke

De Gruyter, Berlin, Germany

Karl Lackner

University of Mainz, Institut for Clinical Chemistry and Laboratory Medicine, Mainz, Germany

\section{Giuseppe Lippi}

University of Verona, Section of Clinical Biochemistry, Verona, Italy

\section{Bohuslav Melichar}

Palacky University Medical School and Teaching Hospital, Department of Oncology, Olomouc, Czech Republic

\section{Deborah A. Payne}

American Pathology, Partners-Unipath LLC - Clinical Trials and Development, Denver, CO, USA

\section{Peter Schlattmann}

University Hospital Jena, Institut of Medical Statistics, Informatics and Documentation, Jena, Germany 